\title{
Exploring Facility Management (7D) with BIM Considering Quality and Performance Assessment Models
}

\author{
Md. Tanjid Mehedi ${ }^{*}$, and Azizul Hoque Shochchho ${ }^{1}$ \\ ${ }^{1}$ Department of Building Engineering and Construction Management, KUET, Khulna-9203, \\ Bangladesh
}

\begin{abstract}
The fields of Construction Management are so vast these days that it enriched with so many elements contemplate to 7D of BIM (Building Information Modeling). Facility Management holds the 7D position to understand and acquire proper knowledge about the quality and performance of a building structure. The purpose of this paper is to identify research gaps in the field of Building Information Modelling (BIM) in the Facility Management (FM) business, as well as practical issues that facility management professionals face while using BIM. The key to successful BIM deployment in the FM business is to improve communication among various stakeholders throughout the project lifecycle. However, there is still some debate over the value of FM in the construction business. To put it another way, construction does not comprehend FM. There are also concerns about interoperability and data exchange. The Quality of information is connected with PIM and AIM with various IQ perspectives. It is determined that BIM-based FM procedures have the potential to change not just the perspective of the FM sector, but also the perspective of the whole industry, as they are based on a collaborative approach to the delivery of intelligent facilities.
\end{abstract}

\section{Introduction}

Building Information Modelling (BIM) is defined as "an IT-enabled method that entails applying and maintaining a holistic digital representation of all building information in the form of a data repository for all phases of the project lifecycle" [1]. According to research, a large proportion of private and public owners think that creating skills in their businesses to employ BIM for the operational phase is critical. The full and precise information offered by given models, according to owners, is a fundamental benefit of adopting BIM for the operation and maintenance [2]. In reality, BIM considerably works as a great source of information backbone for Facility Management systems, enhancing operational workflow efficiency when combined with sophisticated technology. BIM is evolving from a basic data storage system to a source enriched with executing many types of analytics on field data [3]. All the facts about construction process, specific improvements in different

"Corresponding author: mdtanjidmehedikuet16@gmail.com 
aspects and the prosperous activities are all things where performance measurement comes to handy [4].

Why isn't BIM being used for FM decision-making, even though it contains a wealth of building design and construction data? Peer-reviewed research that examines several concerns and problems hindering BIM's implementation in the FM sector can provide answers to this topic. Owners, for example, are primarily thought about the fundamental expenses of a building, omitting to consider later expenditures spent throughout the building's Operations and Maintenance (O\&M) phase [5]. Furthermore, during design phase, when BIM begins to evolve, facilities managers' feedback is not taken into account. As a result, FM decision making is needed to meet up insufficient information data [6].

Building Information Modelling (BIM) considers the innovation which can enhance the construction area in terms of great management and vast capabilities. Lastly, BIM aims to build a dynamic model of a facility that may be utilized throughout the project life cycle [7]. BIM is a computer simulation of an accurate virtual depiction of a building. This model considers precise information for constructing a structure at many phases of a project in different aspects [8].

Agents in charge of technical assessments of buildings completing Post-Occupancy Evaluations can benefit from mobile AR in this context (POE). AR may allow for a more accurate impression of resident interventions, assisting in the adjustment of future developments. POE is a method for evaluating the built environment after it has been occupied over some time [9]. This approach can show building retrofits done to adapt to users' requirements or change of function, in addition to detecting user happiness, building performance. Residents' retrofits show essential elements and values that may be integrated into the design process of similar new structures. Traditional data collection for retrofit detection relies on human recollection and a researcher's disciplined observation of the built environment in contrast to the original design. As a consequence, if POE for retrofit detection is based less on users' memories and more on accurate observation, the outcomes might be more efficient. As a result, POE could be able to express this advantage by using its resources to identify reforms. In this case, Building Information Modelling (BIM model) shown against a genuine build and utilized building may be employed. It's a potential approach for getting the advancement of the art in visualization in architecture, design, construction, and facility management specially with POE.

\section{Methodology}

BIM has an understandable and user friendly nature which functions as a lifecycle with the interdisciplinary 3D data store capacity truly can improve Facility Management (FM) activities. The Project Lifecycle Phases (PLPs) are more likely to consider information exchange as a proper evaluation. Due to lengthy building life cycles and the fact that the pace of new construction is rapidly moving to rehabilitation and maintenance (R\&M). The curiosity of existing structures, facility management (FM) and asset management are also important factors to enhance productivity and efficiency in the AEC/FM sector.

Information and Communication Technology (ICT) has been growing response to a more complicated world. Many FM stakeholders, such as facility managers and building owners, have started to use CAFM software and Facilities Information Systems to help with building asset management and maintenance [10]. Building Information Modelling (BIM) is a recent major shift in ICT for the FM industry, as a consequence of so much benefits with proper resource usage that impacts on all period stages of the construction facility can offer [11].

The methodology considers various information gathering and technical phases to address the questions below: 
1. What type of information does a client require to create accurate models?

2. What are the key IQ elements and associated characteristics required for systematic interpretation and assessment of the models?

3. How might intelligence tests be used to assess a BIM's conformity to owner-specific requirements?

The framework consists of three FM terms, that are Asset (equipment), Spaces (room, corridors etc.) and MEP systems. The required criteria for FM use with a specified value must be included in the modelled assets in a mechanical BIM. In general, these characteristics can be divided into three groups:

1. Asset fabrication attributes: these are necessary for locating extra data about the asset, such as paper works, specification and so on.

2. Asset performance facts: these vary depending on how the asset is and other criteria.

3. Geometric qualities: these are the dimensional qualities that are normally computed understanding facts on geometry of the site and spatial quality checks with asset accessibility and transportability. Using 3D BIM authoring tools, on the other hand, implies that all components will have geometry properties. As a result, we don't check this category in our evaluation.

\subsection{Quality of Information}

Users can develop context-specific and relational knowledge by further processing information and integrated data. Active data processing considers the significance so that it adds to the receiver's knowledge and becomes a part of his or her know-how. [12]

Table 1. BIM-IQ Analysis Framework for FM

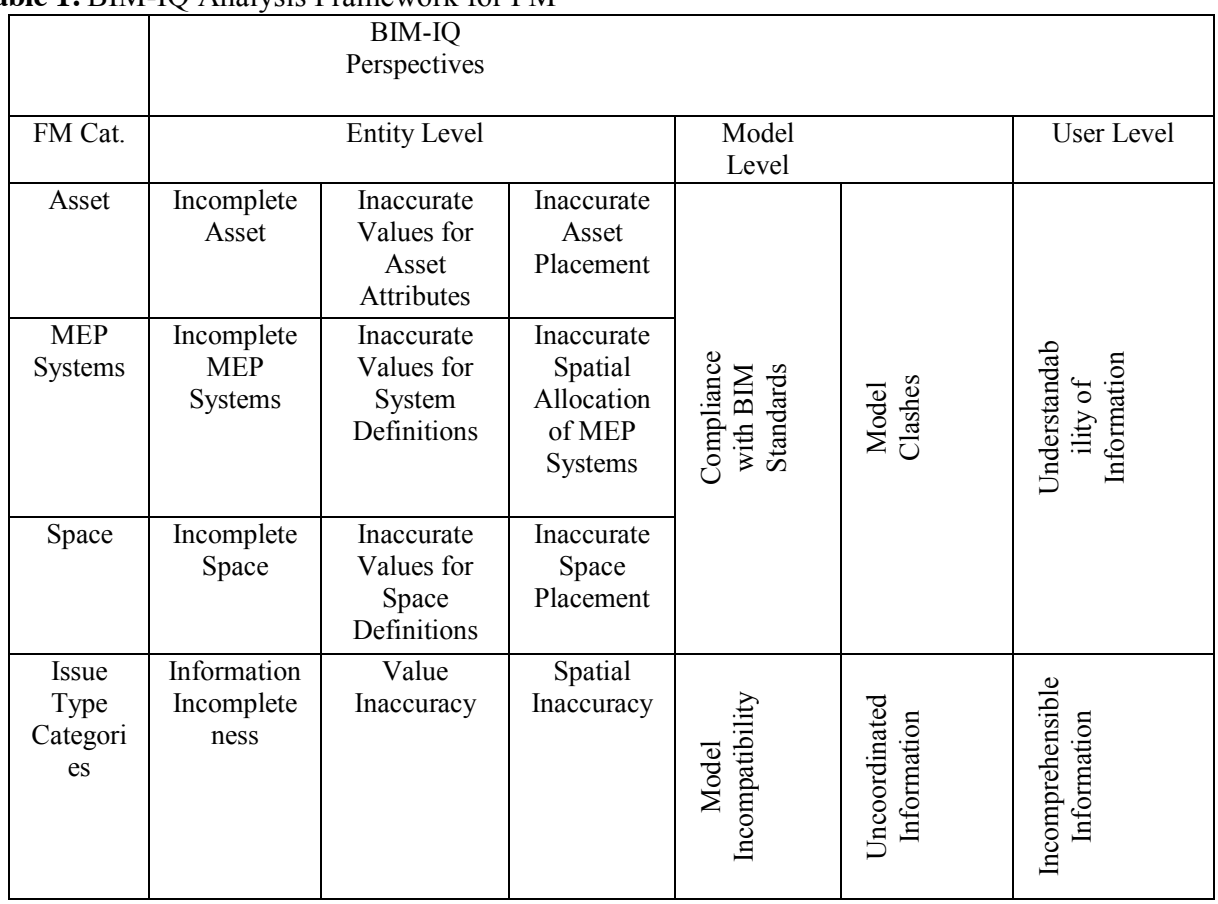

Analyzing the information quality assists to identify the value of that information with the understanding to the user. User's situation defines the value of information and the problem addresses with proper validation. The results of poor information quality's negative 
impacts involve the fact of how to reduce waste and therefore improve value criteria [13]. One solution to this problem may be to use BIM in the field of FM. BIM is simply a data and information system in and of itself, but it has already been shown to remove many of the causes identified when the related processes and work practices are also not remaining unchanged [14]. So the usage of many models and other considerable tools to correct the unwanted possibilities in the project life cycle. The Models shown in this paper has the capability to incorporate the Facility Management with proper analysis and give proper knowledge on the 7D concept. In every construction facility the FM prohibitions should follow strictly with the BIM-IQ analysis which shown in Table-1. The perspectives are considered in various levels with categories.

\subsection{Space Management}

First and foremost, asset owners must be aware of the business processes that happens in the site. This criterion requires for actual space divisions, site standard adjustments and suitable departmental allocations. The value of BIM in terms of facts cannot be emphasized, as it enables space planners to take use of its visualization and coordination capabilities by speeding up the moving process, predicting space needs, and have the simplification about the management process [15]. Also the management needs to follow the code assigned for particular regions.

\subsection{Retrofit Consideration}

The feasibility of a project considered as a main thing with the help of contractual facts. BIM offers a strong basis for planning and feasibility studies by using a historical database of the existing building as a reference for the cost calculation of the proposed improvements. Renovation, refurbishment, and destruction should all be done in a smooth way due to the appearance of a BIM model that enables visual information to be given to the targeted buildings [16].

\subsection{Safety/Emergency Management}

According to [17], critical and sensitive data is protected and only accessible to those who need it. This indicates an improvement in security, but it should be noted that when given access to, such a solution still leaves the potential of data misuse. As a consequence, asset owners must ensure that data security solutions for BIM are in place. FM employees are in charge of minimizing life-threatening hazards and helping emergency units with their responsibilities during an emergency.

To dissolve quickly and effectively, it is crucial to have relevant data in place, structured in permissible way. If comprehensive information was accessible even before rescue personnel arrived, professionals might better plan a response and recovery strategy. One of the researchers developed a BIM-based emergency system that generates evacuation routes, depending on the user's location and transmits two-way data [18].

\section{BIM for Facility Management}

Despite BIM's success in design phases, efforts transferring to the management criteria facility development phases are still a mess. FM is comparatively a recent use of BIM. In the middle of $1990 \mathrm{~s}$, the issue of data transmission had to be handled to properly utilize management information during the FM phase. Interoperability between hundreds of software products on the market was non-existent that time. In 1995, the Industry Alliance 
for Interoperability (IAI), a group of twelve firms, established a relational model for the non-users in the construction site. Industry Foundation Classes, or IFC, was the name given to the final data model [19]. The alliance now publishes, maintains, and updates IFC. IFC supports around 150 software programs globally as a vendor-independent, open standard format. Because of the IFC format's interoperability, designers, contractors, and owners may use different tools throughout the construction phase without carrying the data loss in sharing the file or disruption in interoperability of software [20].

The majority of this information comes from prior lifecycle periods (for example, the capital/delivery phase of building projects). As a result, the interaction between the construction phase and the O\&M phase is critical for managing a building asset in case of project-life expenses to:

- construct an identical, full, and understandable Asset Information Model capable of exchanging valuable data with PIM;

- amend AIM as per corrections in the design every time data need to be updated, information transfer methods across lifecycle phases are required.

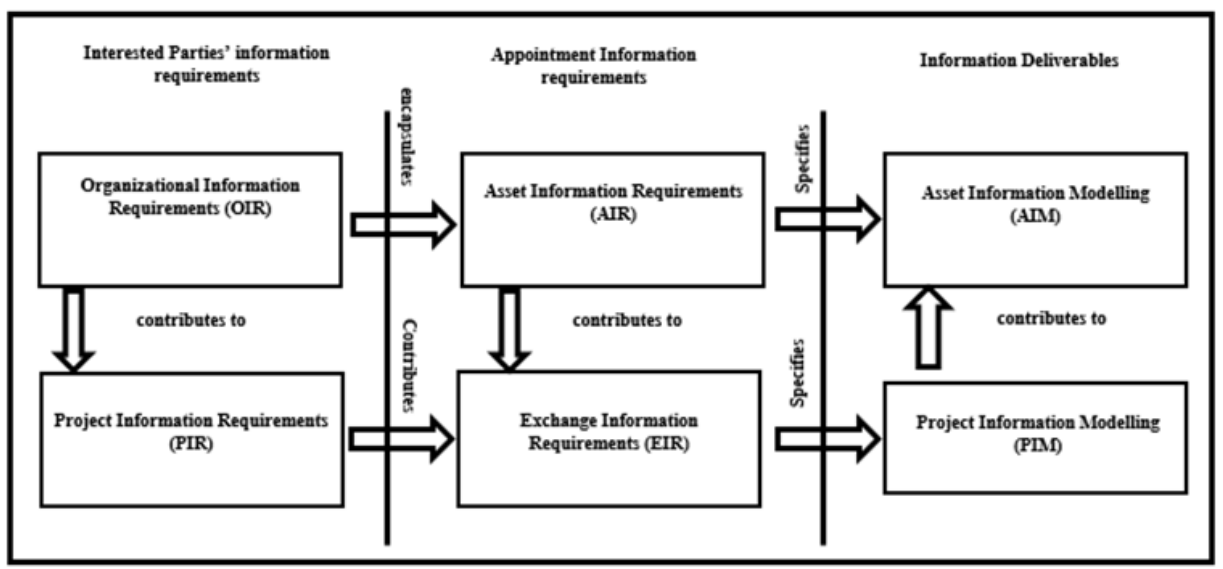

Fig. 1. Relations between the OIR, AIR, and AIM

The AIM must first be compacted with Project Information Modelling data, and that must regularly convert in the time of an asset's operating existence. Including the handover from design and building periods, also day-to-day operations and maintenance.

In reality, the Asset Information Model must serve as both a data warehouse and a way of accessing and receiving information. Collecting data from stakeholders engaged in between phases specially in the first phase. The committee is then responsible for maintaining AIM during building use phase described in Fig. 1 about the data model and by the crossreferences to the existing system.

The company must specify the information interchange between current enterprise systems and AIM based on the requirements and facts about management with other stakeholders participating in FM operations. For example, what sort of categorized data provided designated working teams for their support in the project or projects must be explicitly stated. As a result, considering OIR with reference to Asset Information Requirement (AIR) defines the structure, procedure, and related collectives of information should contain in, shared identically with, or connected with the works of organization attributes. Information interchange with the help of tools are acceptable vastly and can match the need for Facility Management (FM) progress in a typical construction project. Only an exact personnel in this field can lighten about the importance of modelling standards. 


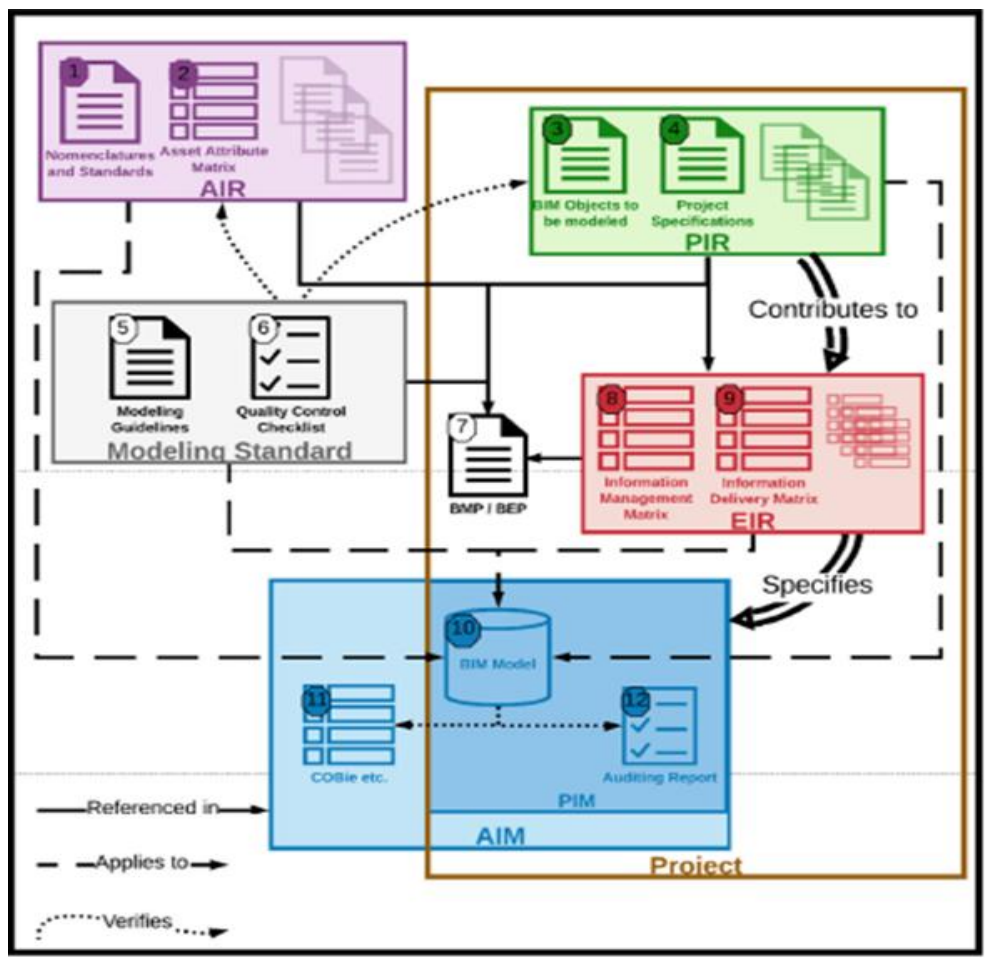

Fig. 2: Modelling standard Considering AIR, PIR, and EIR with the FM system

Project Information Requirements (PIR) are the information needed in a given project to inform decision-making on high-level strategic objectives across the course of the project's life cycle. Excerpts from construction and project management documentation, as well as purpose-written reports such as cost and progress reports, may be required.

The Asset Information Requirements (AIR) are a collection of specific and computable data required to respond to the OIR. They are generally computable and essentially lay out the technical features of the relevant asset information.

The Exchange Information Requirements (EIR) contain information about stakeholders' roles and duties, information production processes and procedures, data standards, file formats, and information exchange timeframes. The EIR is primarily concerned with who, how, and when information is delivered.

Project Information Modelling (PIM) and Asset Information Modelling (AIM), which comprise techniques, scheduling and pricing, details of systems and components or documents, models, and structured data, should not be confused with a virtual model. PIM contributes to the AIM, which is a deliverable supplied by the delivery team in response to the AIR and helps to ensure that the project is delivered on time. The AIM assists with both strategic and day-to-day FM operations. The given data can be described in Fig. 2 as a refurbishment or extension of an existing asset which is planned.

\subsection{BIM Data Quality Assurance and Control}

Quality is defined by some characteristics of a product meets the client's expectations and is judged fit for use (ISO 8402:1994 and 9000:2000). Quality Assurance and Quality Control are two areas of quality management that are intertwined. Quality assurance is a proactive, process-based method to ensuring product quality. Its main goal is to eliminate flaws in 
deliverables from the planning and design phase, ensuring correct modelling from the outset. QA aids in the early understanding of the product's requirements and expectations, as well as the development of a plan to achieve these objectives. To achieve these goals, meticulous preparation and rules are required.

Quality control is a reactive technique based on products that aid in the correction of problems in deliveries. The major goal of the quality control procedure is to ensure that the product meets the specifications. This procedure entails locating any product flaws, repairing any that are discovered, and validating the deliverable.

Quality assurance and control are understandable mutually; the basic difference is quality control gets input from the assurance process, and its feedback aids in the quality assurance process is updating. The improved procedure aids quality assurance personnel in ensuring that the fault does not repeat.

\subsection{POE (Post Occupancy Evaluation) and AR (Augmented Reality) in Quality Assessment}

Preiser, Rabinowitz, and White (1988) processed the POE model which involves three phases: planning, conducting and applying (Fig. 3a). It is proposed that one activity of the planning phase, namely the construction of research tools, be completely restructured to incorporate AR. Other actions outlined by Preiser, Rabinowitz, and White (1988) for this first planning phase are expected to remain unchanged as a result of the adoption of AR. The conducting phase of POE includes the field data gathering method, monitoring and controlling data, collecting, and eventually data analysis. This phase necessitates a complete reorganization due to the disparity in data collection instruments.

Two POE studies have been prepared and will be compared to evaluate the effectiveness of using AR for retrofit identification.

This article presents and discusses data for a new proposal for research instrument development activities during the planning phase of POE with AR (Fig. 3b). Three steps are proposed for this activity: 3D modelling, model treatment, and AR application creation. Because the design of the social housing in this study was established using this type of representation, 3D modeling begins with a $2 \mathrm{D}$ drawing. A BIM model is created and exported to a data format that may be used as input in AR application. The model must be handled to achieve transparency, which will allow for the visibility of superimposed items (real x virtual). The model must also be processed to make it lighter and simpler so that it can be used and manipulated in a mobile AR application. Finally, the processed model is loaded into the mobile AR application and instantiated for the research site, which necessitates model positioning and scaling.
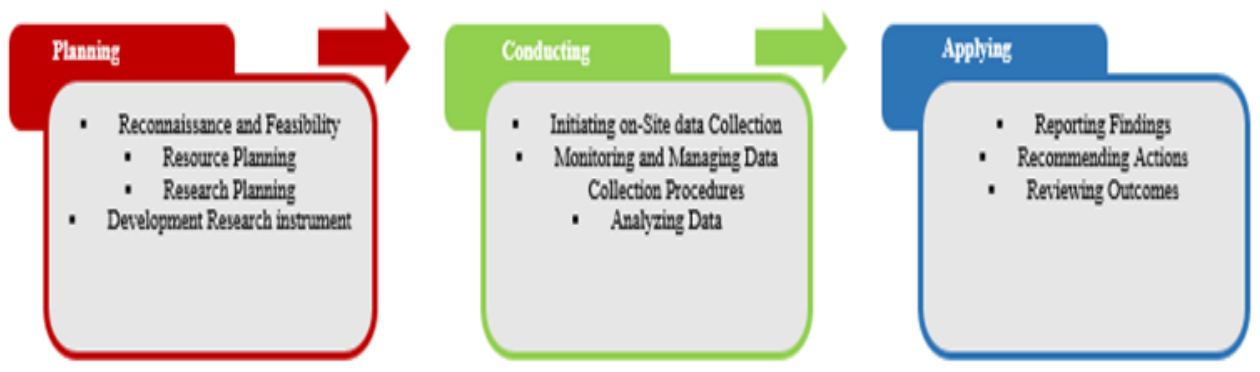

Fig. 3a. The POE process model indicating activities that will be adapted and used for analysis 


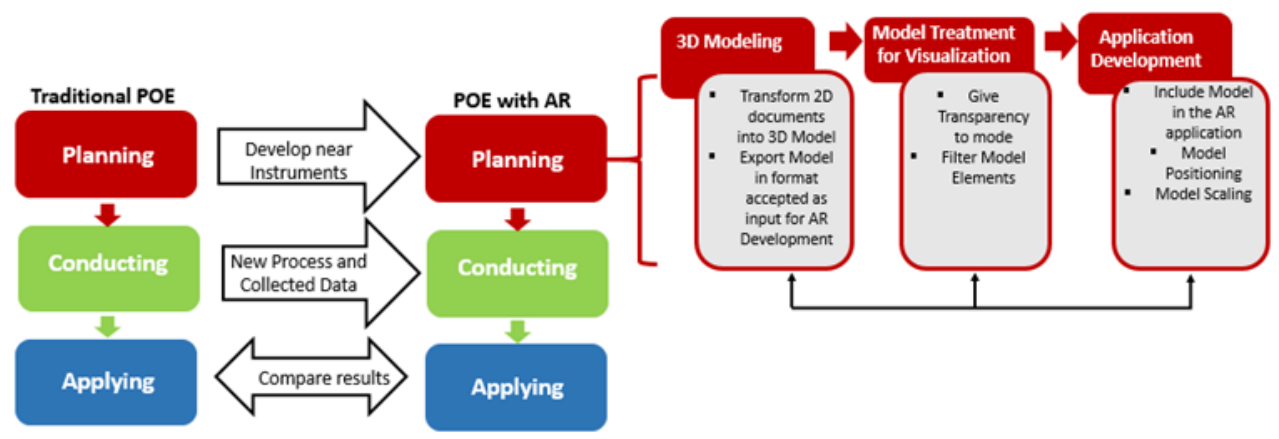

Fig. 3b. The relation between two POE studies in development and detailing of transformation of the activity of research instrument development in the Planning phase of POE with AR

LOD 500 is adopted in the model to support FM activities. All the components and systems of the building are modeled and their dimensions, shape, position, orientation and quantity are matched with the design specification. The model elements may also be attached with non-geometric information.

\subsection{Standardization of the format of information exchange and transfer}

Interoperability has become an issue because most of the widely used software work in silos. Private vendors seeking to push their goods onto the market create a lot of complexity in the industry, thus it's critical for the BIM community to step up its efforts to establish nonproprietary methodologies. Furthermore, as noted in the literature, it is still unclear which facility data should be provided when and how [21].

\subsubsection{COBie Standardization}

To overcome these issues, COBie(Construction Operations Building Information Exchange), a subset of IFC, was introduced. The recent release of BS 1192-4, which replaces COBie-UK-2012, is designed to resolve all of the issues raised by the previous standards, allowing for more effective purchase and maintenance of building assets. A cloud-based strategy to improving interoperability is a popular topic in literature, and it is often regarded as the best course of action for future development. The industry should focus on building web-based BIM exchanges that incorporate both IFCs and SML (Simple Markup Language) files using the cloud platform [22].

The emergence of COBie has come with a specialized information model, which suits requirments of FM professionals. This has provided advantages in the course of cloud based BIM.

\subsection{COBie Project Parameters}

COBie was expected to make the smooth transfer of facility information into the CMMS, which in this pilot project was AIM. Manually entering project information into FM systems would normally traditionally take months. During the project's building phase, the BIM consultant team entered the information of equipment into the BIM model. During commissioning and occupancy, the FM team would typically begin recognizing and tracking this information. Furthermore, the barcode system employed during the construction period includes components of the building that would ordinarily be tagged, barcoded, and then recorded by the FM team. Consultants in charge of BIM collaborated 
with the general contractor Together, they created method for the FM team which would give a separate tag for each of the information and create bar codes and serial numbers for all the things in the list. Each item in the list would be tracked.

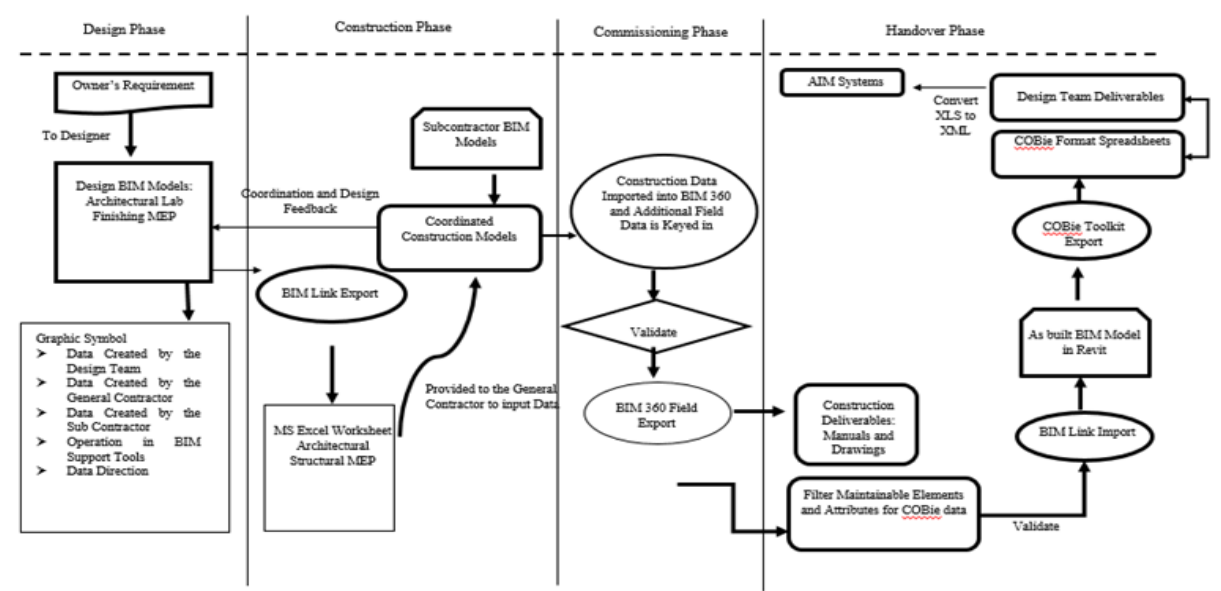

Fig. 4. COBie data categories defined as Project Parameters in Revit

This list was loaded straight in the AIM system after being marked BIM 360 Field. As a result, during the handover phase, the FM team had to do very less work because, most of the work was either in progress or complete (in virtual), after the facility was occupied.

The O\&M documentation files were always supplied to the BIM consultant team as well as the general contractor. They looked over the documents and entered the data into the BIM.. BIM contained only the serial number of the O\&M files corresponding to the components and systems of the building. After the handover, the documents were submitted into the AIM system directly by the plant managers. AIM had been supplied with the asset information tracked via BIM and so the job was done rapidly. Uploading the right document in the page of AIM system containing asset information, was the only job left for the facility managers.

\subsection{Significance of Performance Measurements}

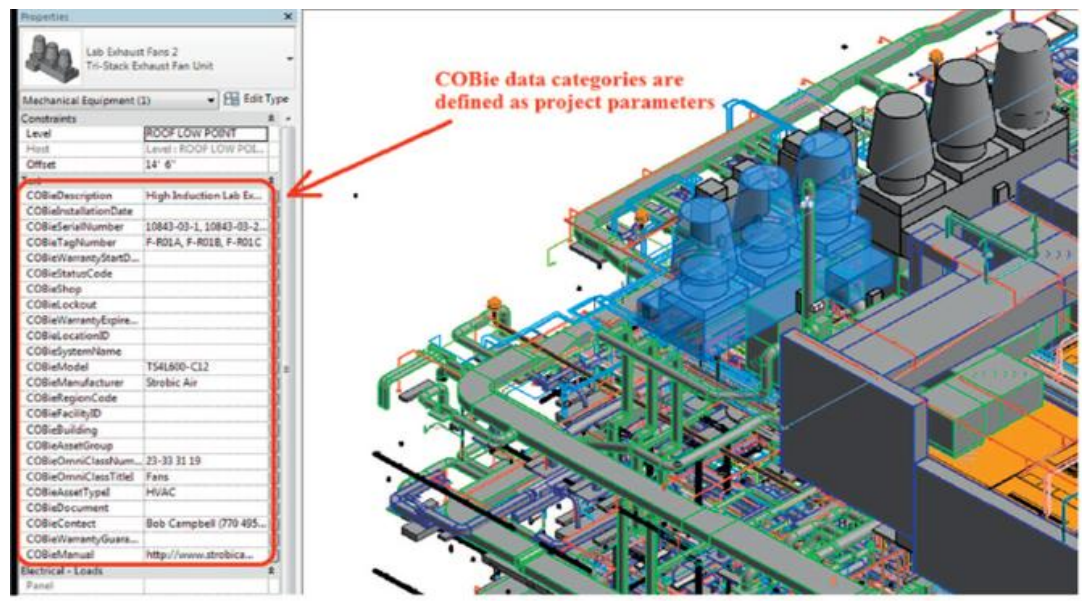

Fig. 5. The FM-enabled BIM workflow used in this project for capturing, managing, exchanging project information 
The performance of FM was found to be in $95.9 \%$ of the examined organizations in this study, whereas the surveyed organizations who did not use any performance assessment was just $4.1 \%$. Performance measurement is deemed "very important" by $52.1 \%$ of respondents and "important" by $41.1 \%$ of respondents. "Slightly important" was only $6.8 \%$ and "Not important" didn't even had any responses. It is understood that, the vast majority of FM practitioners and organizations understand the value of performance measurement and accept performance measurement as a management technique.

\section{Technical tools for Performance measurements}

\subsection{Models of performance effectiveness}

Three of the most used performance models in FM organizations are BEM, BSC and KPI. according to the statistical analysis. The response rates of BEM, BSC and KPI are 5.7\%, $30.0 \%$ and $35.8 \%$ respectively according to statistical analysis. Furthermore, $17.1 \%$ of the studied organizations choose a combination of the KPI and the BSC, while 5.7 percent choose a combination of the KPI and the BEM. Other models, such as 6 Sigma and custom systems, make up 5.7 percent of the total.
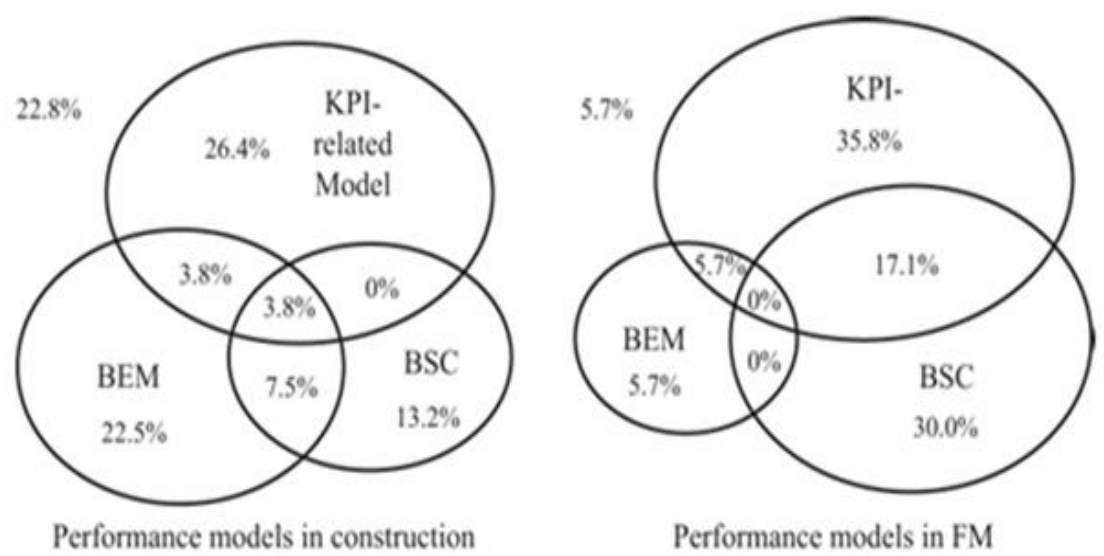

Fig. 6 Comparison of Performance Models

As can be seen Fig. 6 shows how performance models for FM and construction are similar: the KPI, BSC, and BEM are top the three in ranking; KPI got the most extensive acceptance; both FM and construction disciplines use a combination of the KPI and the $\mathrm{BEM}$, and CMM is hardly used by any of the two community [23].

\subsection{Collaborative Design Approach to the Facilities Management}

The asset owner-facility manager or end user-facility manager integration should not happen in early in the project delivery process. Otherwise, the O\&M phase may suffer critical consequences [24]. FM professionals are very knowledgeable about end-user expectations. So, their role in creating the requirements of the owner is advantageous to both parties. Based on this relationship, the magnitude of detail required in the BIM model can be efficiently determined. The LOD (level of development) must represent business requirements, and for the FM team, a lower level of detail may be appropriate in many circumstances [25]. 


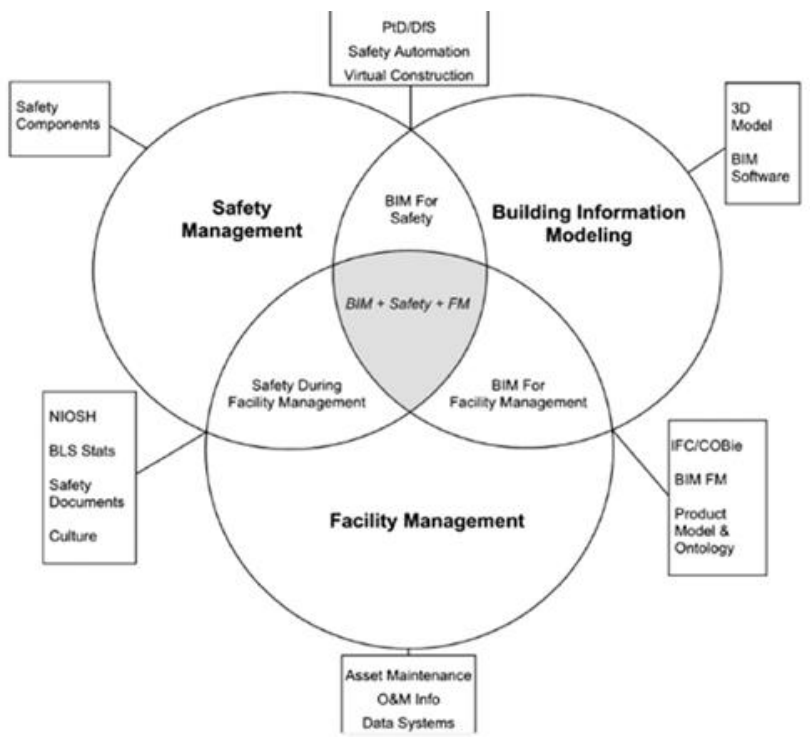

Fig.7. Attributes of the safety factors in Facility Management System

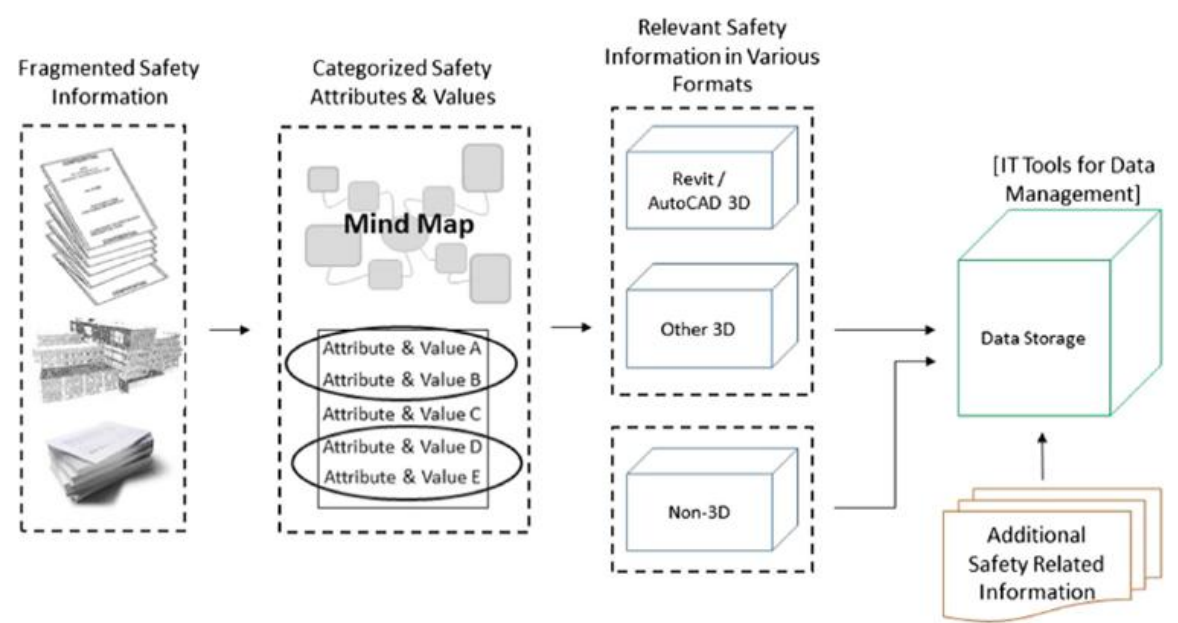

Fig. 8. Literature Analysis Venn Diagram

\section{Conclusions}

Understanding traditional FM processes allows for the identification of a performance gap, which is largely because of insufficient collaboration among different parties and inadequate management of information throughout the building asset lifecycle. Thankfully, BIM comes as an approach which not only allows collaboration but also supports a lifelong logistics of information. Raising awareness about of application of FM in BIM-based activities is the first step in understanding the potential of 7D BIM.

This study introduces scholars and leading practitioners to the obvious idea potential by offering specific proof of BIM application for FM techniques. Studies with a more case studies can greatly contribute to establish and validate the practical feasibility and applicability BIM 7D in the construction sector. The coordination and storage of safetyrelated information is a fragmented system plagued by disorganization and incorrect 
identification, resulting in inefficient retrieving of information related to safety. Due to the present inconvenient state of the system, FM workers may choose to ignore safety advice, increasing the risk of accidents, illnesses and even fatalities. The chance of reference will improve by consolidating necessary safety information and offering a simple mechanism for receiving this complete knowledge, reducing some of the dangers connected with FM operations.

Cultural shifts and interoperability issues are the two hardest hurdles to overcome. The latter is constantly being produced, and it is expected that technical improvements (such as cloud-based apps) and government efforts (such as BIM development groups) will soon be able to address it. Nonetheless, the authors argue that the construction industry's failure to collaborate, rather than a lack of technology answers, is preventing the sector from achieving a BIM-based revolution.

The collaborative and synchronized nature of BIM provides a lifecycle and interdisciplinary 3D data store, can help to improve and address FM related activities, which are currently hampered by fragmentation in the construction industry and a lack of information exchange between Project Lifecycle Phases (PLPs). Because of extended life cycles of buildings as well as the shift towards to repair and maintenance (R\&M) of existing structures instead of building new structures, facility management (FM) and asset management are also the keys to a more productive and effective method working in the AEC/FM sector.

FM practitioners hardly use CMM, unlike KPI, BSC and BEM. Different methods can be used to assess and enhance performance. This conclusion is drawn from the difficulties of keeping 3D stuff static while traveling in one direction but not when rotating around a fixed point. It was also tough to get a 1:1 scale to site visualization by altering the $3 \mathrm{D}$ content scale. Modeling application's unit (mm or $\mathrm{m}$ in ArchiCAD, REVIT, or Sketchup) impacted this method. The 3D content (or BIM model system's coordinate origin also has an impact on visualization on-site, limiting/or upsetting scale changes (small movements may take 3D content out of the site with difficult recovering).

Still, in terms of off-the-shelf technology for mobile AR, the fact that 3D material must be uploaded and displayed in real-time via the Internet demonstrates the necessity for and reliance on a solid connection that favors information download time. 3D models in POE research, on the other hand, are huge in size and must be detailed for exact comparison. BIM models for facility management, which describe the state of a structure, are extremely detailed (LOD 500). As a result, simplifying 3D material for upload and download performance difficulties seem counterintuitive. In this scenario, a happy medium between simplicity and representativeness should be established. In this experiment, this was the solution. Only information that did not interfere with the verification of exterior renovations was filtered from the model, therefore the LOD of the model did not alter (as window glasses, internal equipment, and so on).

In terms of modelling safety considerations, it's worth noting that the initial BIM model must at the very least represent the final condition of the building (when it was delivered to the user). The design drawings for the BIM model utilized did not include precise information on the exterior stairs, ramps, waste disposal, ordinances, and water inflow. As a result, it's important to remember that the model utilized in POE with AR must have all of these original features to do a proper analysis by comparing the material shown. The model flow between apps with interoperability through a succession of export and import processes was used to overcome low interoperability between modelling applications and AR apps (REVIT and Junaio) or between modelling applications. This transformation procedure allows translation between model formats across apps, however, it may result in information loss, which is acceptable and does not hinder the test. However, this remedy to low interoperability adds to the process's complexity. 


\section{References}

1. S. Azhar, M. Khalfan, T. Maqsood, Building information modelling (BIM): now and beyond, Construction Economics and Building 12(4), 15-28 (2015)

2. L. Doumbouya, G. Gao, C. Guan, Adoption of the Building Information Modeling (BIM) for Construction Project Effectiveness: The Review of BIM Benefits, American Journal of Civil Engineering and Architecture 4(3), 74-79 (2016)

3. I. Motawa, K. Carter, Sustainable BIM-based evaluation of buildings, Procedia-Social and Behavioral Sciences 74, 419-428 (2013)

4. G. Hamel, C.K. Prahalad, Competing for the Future, Harvard Business School Press, Boston, MA (1994)

5. P.E. Love, J. Matthews, I. Simpson, A. Hill, O.A. Olatunji, A benefits realization management building information modeling framework for asset owners, Automation in Construction 37, 1-10 (2014)

6. M.K. Dixit, V. Venkatraj, Integrating facility management functions in building information modeling (BIM): a review of key issues and challenges, International Research Conference, CIB W 70 Facilities Management and Maintenance, University of Salford, Manchester (2017)

7. V. Pniewski, Building Information Modeling (BIM), Interoperability Issues in Light of Interdisciplinary Collaboration, Collaborative Modeling Ltd, Third Edition, London, UK (2011)

8. S. Azhar, Building information modeling (BIM): Trends, benefits, risks, and challenges for the AEC industry, Leadership and Management in Engineering 11, 241-252 (2011)

9. W.F.E. Preiser, H.Z. Rabinowitz, E.T. White, Post-Occupancy Evaluation, Van Nostrand Reinhold, New York (1988)

10. R. Volk, J. Stengel, F. Schultmann, Building information modeling (BIM) for existing buildings-literature review and future needs, Autom Constr 38, 109-127 (2014)

11. T. Eastman, L. Sacks, BIM handbook - a guide to building information modeling for owners, managers, designers, engineers, and contractors, Wiley, Hoboken (2011)

12. T. Jylhä, M.E. Suvanto, Impacts of poor quality of the information in the facility management field, Facilities 33(5/6), 302-319 (2015)

13. D.B. Lawrence, The Economic Value of Information, Springer, New York (1999)

14. M. Herrala, P. Leviäkangas, H. Haapasalo, Information value attributes and assessment methods - a construct from a traffic and traveler information perspective, Value World 32, 34-45 (2009)

15. B. Becerik-Gerber, F. Jazizadeh, N. Li, G. Calis, Application Areas and Data Requirements for BIM-Enabled Facilities Management, Journal of Construction Engineering and Management 138(3), 431-442 (2012)

16. R. Volk, J. Stengel, F. Schultmann, Building Information Modeling (BIM) for Existing Buildings - Literature Review and Future Needs, Automation in Construction 38, 109-127 (2014)

17. B. Cox, F. Terry, Creating a BIM for Emergency Management, Journal of Building Information Modeling, Fall 2008, 24-25 (2008)

18. B. Wang, H. Li, Y. Rezgui, A. Bradley, H.N. Ong, BIM Based Virtual Environment for Fire Emergency Evacuation, The Scientific World Journal 2014, 22 (2014)

19. A. Borrmann, J. Beetz, C. Koch, T. Liebich, S. Muhic, Industry Foundation Classes: A Standardized Data Model for the Vendor-Neutral Exchange of Digital Building Models. In: A. Borrmann, M. König, C. Koch, J. Beetz (eds), Building Information Modeling, Springer, Cham. (2018) 
20. P. Teicholz, BIM for Facility Managers, JohnWiley \& Sons Inc, Hoboken, New Jersey (2014)

21. B. Wang, H. Li, Y. Rezgui, A. Bradley, H.N. Ong, BIM Based Virtual Environment for Fire Emergency Evacuation, The Scientific World Journal 2014, 22 (2014)

22. A. Redmon, A. Hore, M. Alshawi, R. West, Exploring how information exchanges can be enhanced through Cloud BIM, Journal of Automation in Construction 24, 175 183 (2012)

23. M. Yalcinkaya, V. Singh, Building Information Modeling (BIM) for Facilities Management - Literature Review and Future Needs. In: S. Fukuda, A. Bernard, B. Gurumoorthy, A. Bouras (eds), Product Lifecycle Management for a Global Market. PLM 2014. IFIP Advances in Information and Communication Technology, Springer, Berlin, Heidelberg (2014)

24. W. Qidwai, Advances in Information and Communication Technology (ICT): Issues, Challenges and Opportunities for Health Care Professionals, Journal of College of Physicians And Surgeons Pakistan 21(11), 651-653 (2011)

25. P. Parsanezhad, An overview of information logistics for FM\&O business processes, In: A. Mahdavi, B. Martens, R. Scherer (eds.), European Conference on Product and Process Modelling, Vienna, Austria (2015). 